\title{
CONSERVAÇÃO DO PÓRTICO DE ENTRADA DO CEMITÉRIO DA CONSOLAÇÃO - SP
}

\author{
CRUZ, RENATA SATIE DA \\ Estudante de graduação da FAUUSP \\ Universidade de São Paulo \\ São Paulo - Brasil \\ renata.satie.cruz@usp.br
}

\author{
OLIVEIRA, FABIANA LOPES DE \\ Docente da FAUUSP \\ Universidade de São Paulo \\ São Paulo - Brasil \\ floliveira@usp.br
}

\section{RESUMO}

O Cemitério da Consolação foi o primeiro cemitério municipal da cidade de São Paulo, oficializado em 1868. Em 2005, foi tombado pelos órgãos de preservação de nível estadual e municipal, devido a sua importância histórica e capacidade de representar os valores artísticos e sociais da elite paulista do século XX. Dentre os bens tombados estão o Ossário e o Pórtico de Entrada, projetados pelo escritório de Ramos de Azevedo em 1902. A estrutura do Pórtico é composta por alvenaria de tijolos maciços, revestida por argamassa e pintura à base de cal. Sua fachada possui ornamentos de argamassa armada. A cobertura é sustentada também por duas colunas de granito. Internamente, há trabalhos em alto relevo com motivos religiosos nas paredes. Infelizmente todo esse acervo arquitetônico e artístico encontra-se sem manutenção e apresenta sérios problemas patológicos. O objetivo deste artigo é verificar o estado de conservação deste monumento através da análise do Mapa de Danos, cujos dados foram obtidos com auxílio da termografia. O Mapa de Danos é um documento para o diagnóstico das manifestações patológicas que afetam os bens tombados e possibilita o registro do quadro evolutivo do estado de conservação. A Termografia Infravermelha (TI) é um método não-destrutivo de inspeção que constitui na identificação visual do gradiente de temperatura de um objeto e permite verificar regiões do edifício que possuem comportamento térmico diferente. Isto possibilita detectar os pontos que necessitam outro tipo de inspeção para identificar a intensidade e causa dos danos. Por meio desses registros ter-se-á condições de avaliar a extensão das manifestações patológicas, possibilitando a proposta de ações preventivas de conservação.

Palavras-chave: Conservação, Mapa de Danos, Termografia, Cemitério da Consolação.

\section{ABSTRACT}

The Consolação Cemetery was the first municipal cemetery in the city of São Paulo, made official in 1868. In 2005, it was landmarked by the state and municipal preservation bodies because of its historical importance, able to represent a microcosmos of the artistic and social values of the elite of São Paulo in the XX century. Among the landmarked monuments, there are the Chapel, the Ossuary and the Entry Portico, designed by Ramos de Azevedo's firm in 1902. The structure of the Entry Portico is composed of solid brickworks, coated with sand and lime mortar and ochre pigment. The façade of the frame is rounded with very beautiful ornaments made of reinforced mortar. Internally, there are high-relief works with religious motives on the walls, forming a one-of-kind artistic set. Unfortunately, this whole architectonic and artistic asset of inestimable value has not been maintained and shows serious pathological problems, mainly on its façades. The purpose of this article is to check the state of preservation of this monument by means of analysis of the damage map, whose data has been obtained with the help of thermography. The Damage Map is an important document for the diagnosis of the pathological manifestations that affect the landmarked assets, whose function is to record a graphic representation of their pathological state. Infrared Thermography (IT) is a non-destructive inspection method that consists of visual identification of the temperature gradient of an object. This enables detecting precisely the points that need to be inspected better in order to identify the intensity of the damages. By means of these records, it is possible to assess the extension of the pathological manifestations in the historical asset and its possible causes, enabling proposal of corrective and preventive actions for preservation of the Portico of the Consolação Cemetery. Keywords: preservation, damage maps, thermography, Consolação Cemetery 


\section{INTRODUÇÃO}

Ao longo do tempo, o patrimônio cultural possui sua materialidade ameaçada por vários tipos de agentes com os mais diversos graus de agressividade. Desde ações naturais das intempéries que possuem caráter cíclico; até gestos individuais e pontuais de vandalismo (FUNDAÇÃO CASA RUI BARBOSA). A ausência de manutenção preventiva e corretiva agravam o estado de deterioração do patrimônio arquitetônico a longo prazo.

Diante a deterioração dos bens culturais frequentemente recorremos ao projeto de restauro como intervenção, com o intuito de que valores e significados do patrimônio sejam transmitidos ao longo do tempo. Entretanto, sabe-se que a ação de restaurar, mesmo que bem fundamentada, provoca modificações e reinterpretações inevitáveis no bem cultural (CARSALADE, 2015). Porém, existe um instrumento que complementa a política de preservação do patrimônio cultural e que permite prolongar o estado de conservação do bem cultural antes ou após o processo de restauro: o Plano de Conservação. Ele está alinhado ao conceito de conservação preventiva, que é considerado um método eficaz e econômico de preservar a integridade física dos bens culturais, que possui o objetivo de mitigar o seu processo de deterioração e minimizar a necessidade de uma intervenção de restauro (FUNDAÇÃO CASA RUI BARBOSA). Logo, o Plano de Conservação, com base em um estudo sobre o edifício, estabelece diretrizes para intervenções e manutenção futuras, preservando o seu significado. (CONSERVA FAU)

O Pórtico do Cemitério da Consolação é um dos bens culturais cujo estado de deterioração pode prejudicar a transmissão da sua história. Projetado ao estilo eclético pelo escritório do arquiteto Ramos de Azevedo em 1902, o Cemitério da Consolação é um lugar importante que preserva os valores artísticos e culturais da elite paulista do século XX.

\section{HISTÓRIA DO CEMITÉRIO}

Desde a Idade Média, nas sociedades predominantemente cristãs, havia a cultura de sepultar os mortos dentro das igrejas. Com o aumento populacional e o avanço das epidemias no século XVIII, houve um crescimento do debate dos princípios de higiene e sanitários que deram base para a elaboração do conceito de cemitério. A aceitação dessa solução pela população foi um processo de lenta maturação tanto na Europa como no Brasil. (LOUREIRO, 1977)

O primeiro passo para a implementação do cemitério na sociedade brasileira, foi dado durante o Período Regencial, na Carta Régia de 1801, que proibia o sepultamento em Igrejas e havia a recomendação de um cemitério ao ar livre com certa distância dos aglomerado urbanos. Houve resistência em relação a essa proposta, pois os enterros fora das igrejas eram restritos aos não-católicos, escravos e sentenciados. Somente em 1854, a Câmara Municipal de São Paulo deliberou a construção de um cemitério público geral. (LOUREIRO, 1977)

Em 1855, foi construído o cemitério no alto da Consolação, local afastado dos moradores recomendado pelo engenheiro Carlos Rath. Foi oficializado em 1868, o primeiro cemitério municipal de São Paulo. Em 1902, encomendou-se um projeto para o pórtico, necrotério e muros e, possivelmente, a administração e sanitários para o escritório de Ramos de Azevedo (Figura 1). (CARVALHO, 1996)

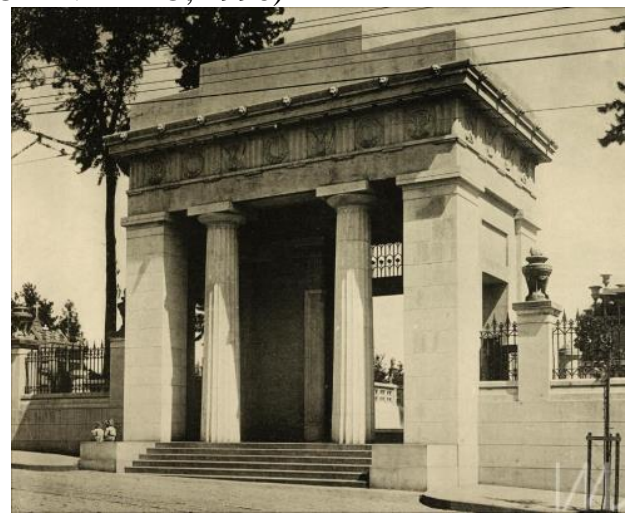

(a)

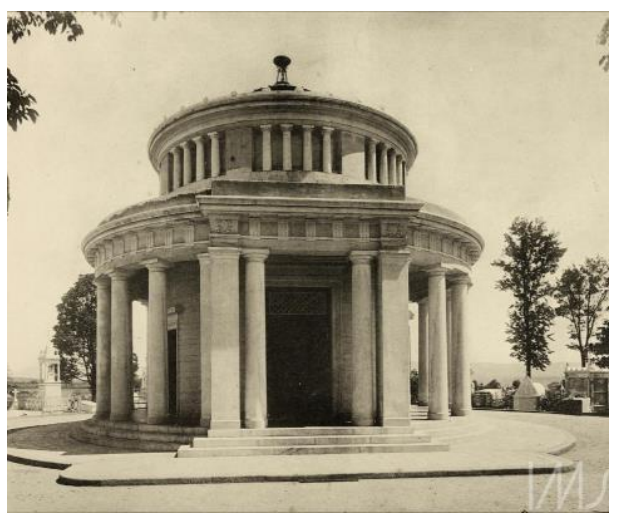

(b)

Figura 1: Pórtico (a) e Ossário (b) do Cemitério da Consolação

Fonte: Quaas, Otto Rudolf (1900 circa). Acervo Biblioteca Nacional 
Durante o século XX, o Cemitério da Consolação foi se tornando um espaço de expressão da elite paulista. Os jazigos e mausoléus foram construídos ao estilo eclético com os mais nobres materiais e técnicas disponíveis. Hoje, o cemitério reúne um rico acervo artístico e arquitetônico, evidenciando símbolos e valores da sociedade do período.

Dada a importância do Cemitério da Consolação, em 2014, os órgãos de preservação municipal e estadual reconheceram seu valor histórico e decidiram por seu tombamento. Nos processos, estão preservados os traçados das alamedas, quadras e ruas, os elementos de autoria do escritório de Ramos de Azevedo, além das esculturas de valor artístico. (CONDEPHAAT; CONPRESP)

\section{MÉTODO}

A fim de produzir uma base de informação para a elaboração de um Plano de Conservação e um mapa de danos do Pórtico, foi feita pesquisa das bases originais de projeto no Arquivo Histórico Municipal de São Paulo e pesquisa iconográfica em acervos de imagem digitais.

Dentre as diversas técnicas disponíveis para a inspeção das manifestações patológicas do pórtico, foi dada a prioridade aos métodos não-destrutivos e aqueles que permitissem a obtenção de dados em grandes alturas sem a necessidade de andaimes. Logo, para a parte experimental foi feito um levantamento por aerofotogrametria e termografia do lado interno e externo do elemento arquitetônico com o uso de drone. Com estes dados qual foi possível obter informações sobre o estado de deterioração e produzir um diagnóstico do Pórtico, representado pelo mapa de danos (Figura 2).

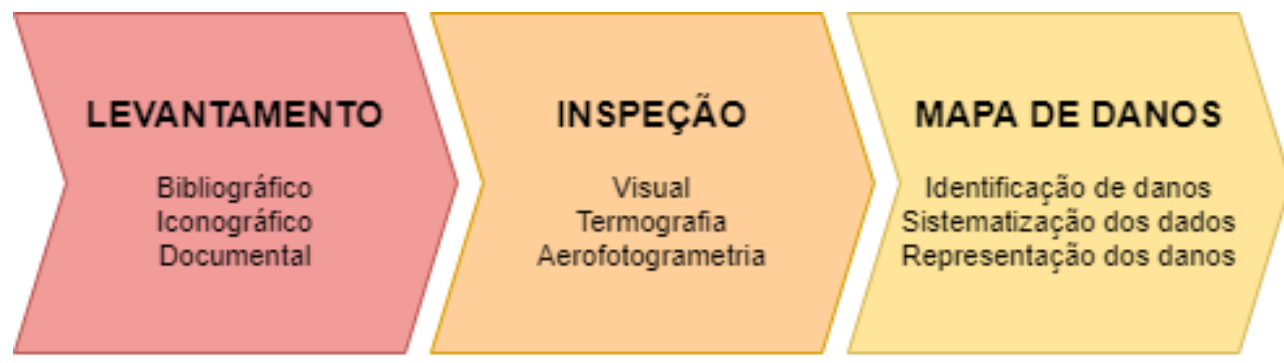

Figura 2: Fluxograma do método adotado para a elaboração do Mapa de Danos

Fonte: Autora, 2020

\subsection{PRESERVAÇÃo}

Como o Pórtico do Cemitério da Consolação é reconhecido como um bem cultural, as intervenções propostas para ele devem respeitar às formulações teóricas de preservação reconhecidos pelos órgãos responsáveis pelo tombamento. Adotou-se a Carta de Veneza de 1964, como documento de base para a formulação do Plano de Conservação, pelo fato de ter sido elaborada para monumentos e sítios históricos.

A Carta de Veneza possui caráter indicativo de posturas a serem tomadas em relação ao patrimônio cultural. As propostas do documento são pautadas no "restauro crítico", que preconiza o respeito pelas várias camadas de tempo do bem e pela distinguibilidade das intervenções propostas, ou seja, deve tornar possível a identificação da ação contemporânea para não criar falsos históricos e prejudicar a leitura do observador. (KUHL, 2010).

Nela está pontuada a importância da manutenção permanente na conservação do monumento. (ICOMOS, 1964) A manutenção faz parte de ações para a conservação preventiva e é definida por um grupo de tarefas rotineiras e não destrutivas que possuem o objetivo de retardar o processo de deterioração e de perda de significância do edifício histórico.(HERITAGE CARE, 2019).

O Plano de Conservação é a concepção, coordenação e execução de um conjunto de estratégias para preservar o bem e reforçar a sua identidade cultural. (FUNDAÇÃO RUI BARBOSA). Nele há a descrição do estado de conservação do bem histórico e as diretrizes para intervenção. Para a elaboração do Plano de Conservação, tomou-se como base o fluxograma das atividades para elaborar intervenções para o edifício histórico da Figura 2. 


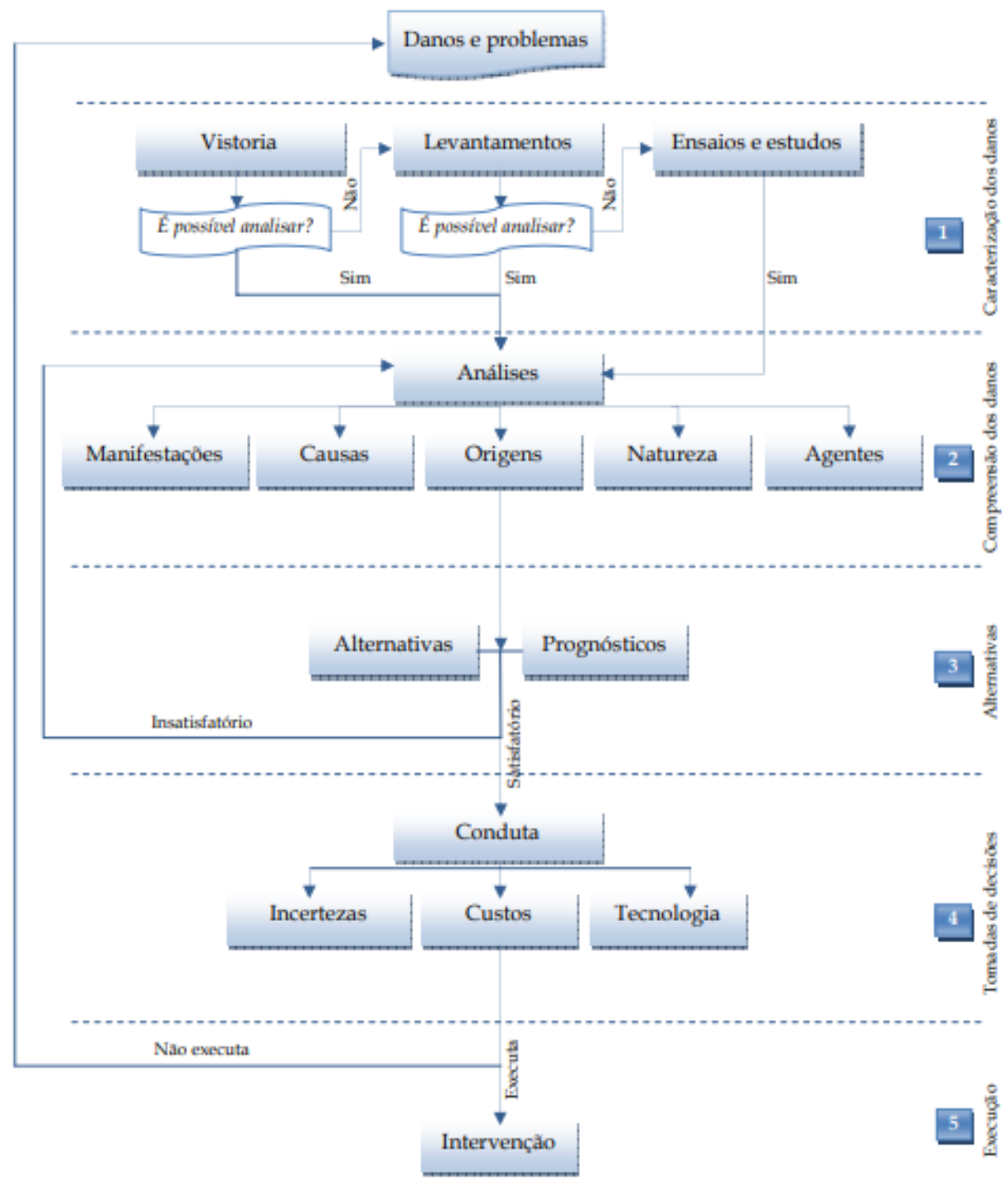

Figura 3: Fluxograma para estudo dos danos

Fonte: TINOCO, 2009

\subsection{CARACTERÍSTICA DO PÓRTICO}

O pórtico de entrada da pesquisa em questão foi projetado ao estilo eclético, caracterizado pela simetria, referência à cultura greco-romana e adornos em argamassa armada. A estrutura do pórtico foi executada em alvenaria de tijolo maciço revestida em argamassa de areia e cal, pintura a base de cal e pigmento. Nas últimas décadas, houve a pintura das fachadas com tinta à base orgânica, criando um filme impermeável para a estrutura do pórtico. As colunas que marcam a entrada do cemitério são feitas de tambor de granito e o acesso é controlado por portões de ferro.

O Pórtico fica localizado na Rua da Consolação, local muito suscetível a material particulado proveniente da poluição provocada pelo intenso fluxo de automóveis na via. O Cemitério da Consolação possui arborização que ameniza a temperatura e cria ambiente de sombra. A orientação do Pórtico está representada na Figura 3 e é possível verificar que as fachadas que recebem maior incidência solar são a fachada sudoeste e a fachada noroeste. A identificação da orientação das fachadas é essencial, devido aos efeitos de degradação que a radiação ultravioleta sobre o material e as movimentações ocorridas por dilatação térmica. 


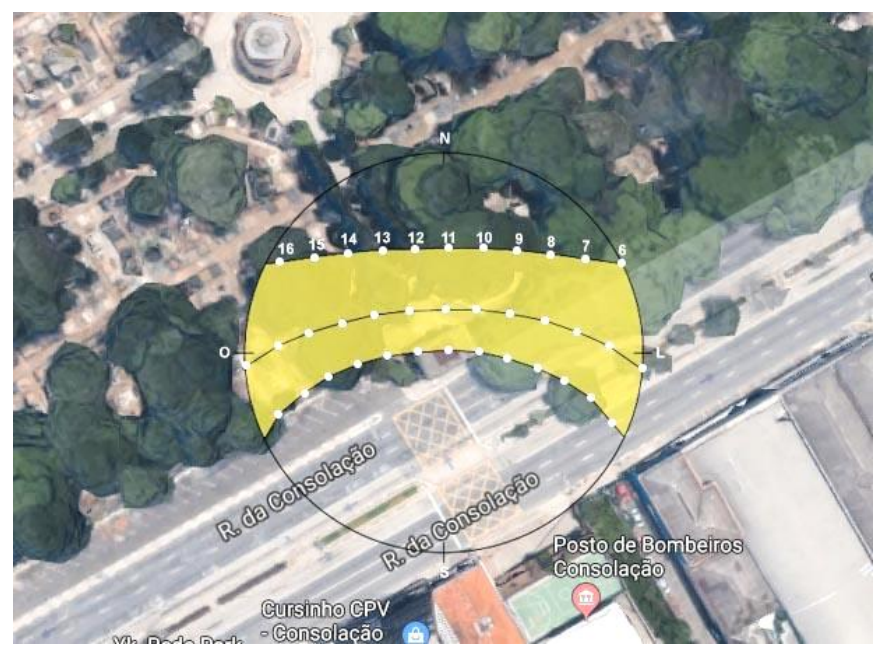

Figura 4: Orientação Solar do Pórtico do Cemitério da Consolação.

fonte: adaptado de https://www.sunearthtools.com/dp/tools/pos_sun.php\#top

\subsection{TERMOGRAFIA INFRAVERMELHA}

A inspeção é uma pesquisa detalhada do edifício para identificar manifestações patológicas e suas causas com a intenção de obter uma visão abrangente do estado de conservação do edifício. A termografia consiste num método não-destrutivo de identificação visual do gradiente de temperatura superficial de um objeto (CORTIZO et al., 2008), que representa a radiação infravermelha emitida da superfície do material por uma matriz de temperatura em escala de cores. O uso de um conjunto de instrumentos sensíveis à radiação infravermelho - termovisores e radiômetros - permite visualizar o perfil térmico e medir as variações de calor emitido pelas diversas regiões da superfície de um corpo sem a necessidade de contato físico com o mesmo.

Com o uso da termografia é possível identificar pontos de desprendimento de argamassa e de tinta e infiltração. A identificação de defeitos na aderência da argamassa, por exemplo, se deve pela diferença de comportamento térmico entre o material íntegro e o material solto (Figura 4). Durante o dia, a radiação solar aquece a superfície do edifício, que estabiliza a uma certa temperatura. O material solto por possuir camada de ar entre a base e menor espessura, absorve mais calor devido a sua maior capacidade térmica. Durante a noite, o comportamento é inverso. A camada de material solto perde calor mais rápido para o ambiente, em relação ao material íntegro (HIASA et al. 2017)

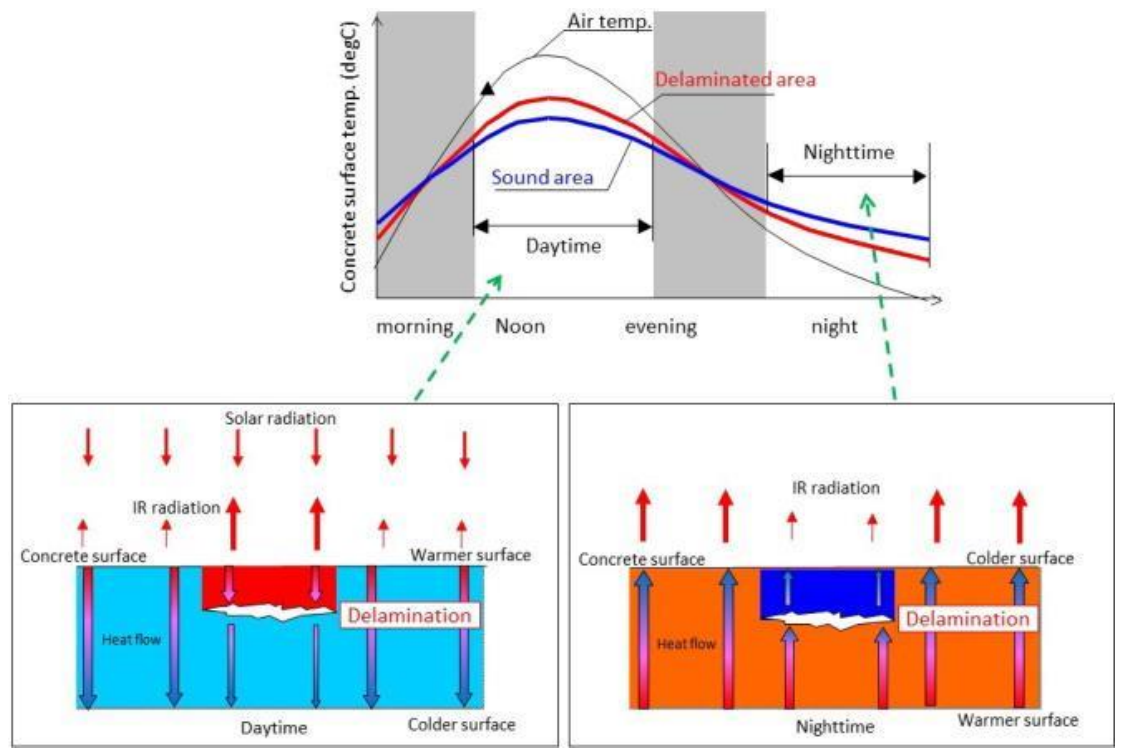

Figura 5: Comportamento térmico - Termografia. Fonte: HIASA (2017) 
Como o comportamento do material é diferente de acordo com o período do dia, é importante registrar as condições da medição para não haver erro de interpretação das informações. No caso, foi feito no período da manhã por volta das 10 horas no mês de agosto. A termografia foi acompanhada pelo levantamento aerofotogramétrico por drone devido à dificuldade de acesso à totalidade do edifício. Esta técnica permitiu obter dados sobre o estado de conservação dos elementos de argamassa da fachada localizados em grandes alturas, do adorno em relevo no interior do pórtico e da cobertura. Os dados obtidos servirão como base para a elaboração do mapa de danos.

\subsection{MAPA DE DANOS}

O processo de inspeção permite identificar diversas manifestações patológicas do pórtico, tais como fissuras, eflorescência, desprendimento de tinta, desprendimento de argamassa, presença de vegetação, presença de umidade, dentre outros. Há um desafio de sistematizar e registrar essas informações de forma inteligível para que outras pessoas tenham acesso.

A síntese do resultado das investigações feitas sobre as alterações funcionais e estruturais nos materiais, técnicas e componentes construtivos é ilustrada no documento conhecido por mapa de danos. Tinoco (2009) define mapa de danos como a representação gráfico-fotográfica, sinóptica, onde estão ilustradas e descritas todas as manifestações patológicas do objeto em estudo. Frente ao número elevado de informações coletadas em pesquisas, vistorias, e estudos técnicocientíficos, o mapa é um documento importante, pois as organiza em um único local, agilizando o processo de elaboração das intervenções necessárias no objeto. Além disso, pode ser utilizado como um guia para o profissional que irá proceder com a manutenção, uma vez que facilita a identificação e a localização dos danos, e como uma referência para determinar o local e a sequência de realização das atividades conservativas, priorizando por exemplo, os danos mais abrangentes ou os mais agressivos.

O registro dos danos foi feito de maneira gráfica e como referência de padrão de representação será adotada a norma italiana NORMAL 1/88 - Alterazioni Macroscopiche dei materiali Lapidei: Lessico. Esta, estabelece hachuras padrão para representar cada uma das manifestações patológicas encontradas em rochas e materiais cerâmicos, além de descrevêlas sucintamente. Apesar dessa particularidade de material tomar-se-á como base o que prescreve graficamente nesta normativa italiana para confecção do mapa de danos do estudo em questão.

Tabela 1 - Lista de danos com descrição e legenda

\begin{tabular}{|l|l|l|l|}
\hline Dano & Descrição & Foto & Legenda \\
\hline Lacuna & $\begin{array}{l}\text { Perda de material e exposição do } \\
\text { substrato }\end{array}$ & $\begin{array}{l}\text { Mudança de aspecto cromático } \\
\text { natural do material }\end{array}$ & \begin{tabular}{l} 
Pátina \\
\hline
\end{tabular} \\
\hline Destacamento & argamassa & & \\
\hline
\end{tabular}


Tabela 1 - Lista de danos com descrição e legenda (cont.)

\begin{tabular}{|c|c|c|c|}
\hline Dano & Descrição & Foto & Legenda \\
\hline Vegetação & $\begin{array}{l}\text { Enraizamento de vegetal no } \\
\text { substrato da vedação da } \\
\text { edificação }\end{array}$ & 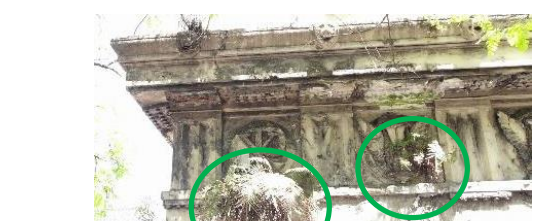 & \\
\hline $\begin{array}{l}\text { Colonização } \\
\text { Biológica }\end{array}$ & $\begin{array}{l}\text { Manchas ocorridas por } \\
\text { aparecimento de musgos, fungos, } \\
\text { bolores, dentre outros }\end{array}$ & 35 & + \\
\hline $\begin{array}{l}\text { Intervenção } \\
\text { Recente }\end{array}$ & $\begin{array}{l}\text { Ações corretivas realizadas nas } \\
\text { últimas décadas. }\end{array}$ & & \\
\hline $\begin{array}{l}\text { Depósito } \\
\text { superficial }\end{array}$ & Acúmulo de sujidades, manchas & & \\
\hline
\end{tabular}

\section{RESULTADOS}

Com base nos levantamentos, realizou-se o mapeamento de danos de cada fachada e da cobertura adotando o padrão gráfico ilustrado anteriormente. A Figura 6 mostra os danos identificados na fachada sudeste, que é aquela voltada para a Rua da Consolação, onde há o acesso para carros e pedestres. Nessa fachada, está presente o uso de granito como revestimento das colunas e pilastras.

Os principais danos identificados na fachada foram: PV-01 (presença vegetal), identificada nas fissuras da cobertura, nas conexões entre os adornos de argamassa armada e o friso e nas juntas das rochas de granito. A maioria dos indivíduos vegetais são de porte pequeno ou médio. PT-01 (pátina), encontrada nos elementos de granito, que se manifesta como uma mancha de cor ferrugem advinda de partículas de ferro da própria formação rochosa. IR-01 (intervenções recentes), representada pela aplicação de tinta na rocha de granito para apagar marcas de pichação, entretanto a tinta cria ruído no aspecto estético da rocha. FI-01 (fissuras), encontrada nas platibandas da cobertura de concreto sob a forma de fissuras horizontais ou que acompanham o caimento da laje de concreto, possivelmente causadas pelo efeito de dilatação térmica da laje de cobertura. DP-01 (depósito superficial), observado em toda a cornija como sujidades e um pouco de desgaste da argamassa. A presença da via com intenso trânsito de automóveis e a localização do pórtico favorecem na causa dessas manchas. DT-01 e DT-02 (destacamentos), na pintura do pórtico. DP-02 (depósito superficial), localizado na região mais alta dos elementos de granito, há o acúmulo de sujidades criando uma mancha negra. PC-01 (pichação), localizada nos elementos de granito na altura do pedestre. Ainda que houve o cuidado de apagar as pichações, outras mais recentes foram feitas. CB-01 (colonização biológica), encontrada no granito na região mais próxima à calçada, criando manchas esverdeadas. 

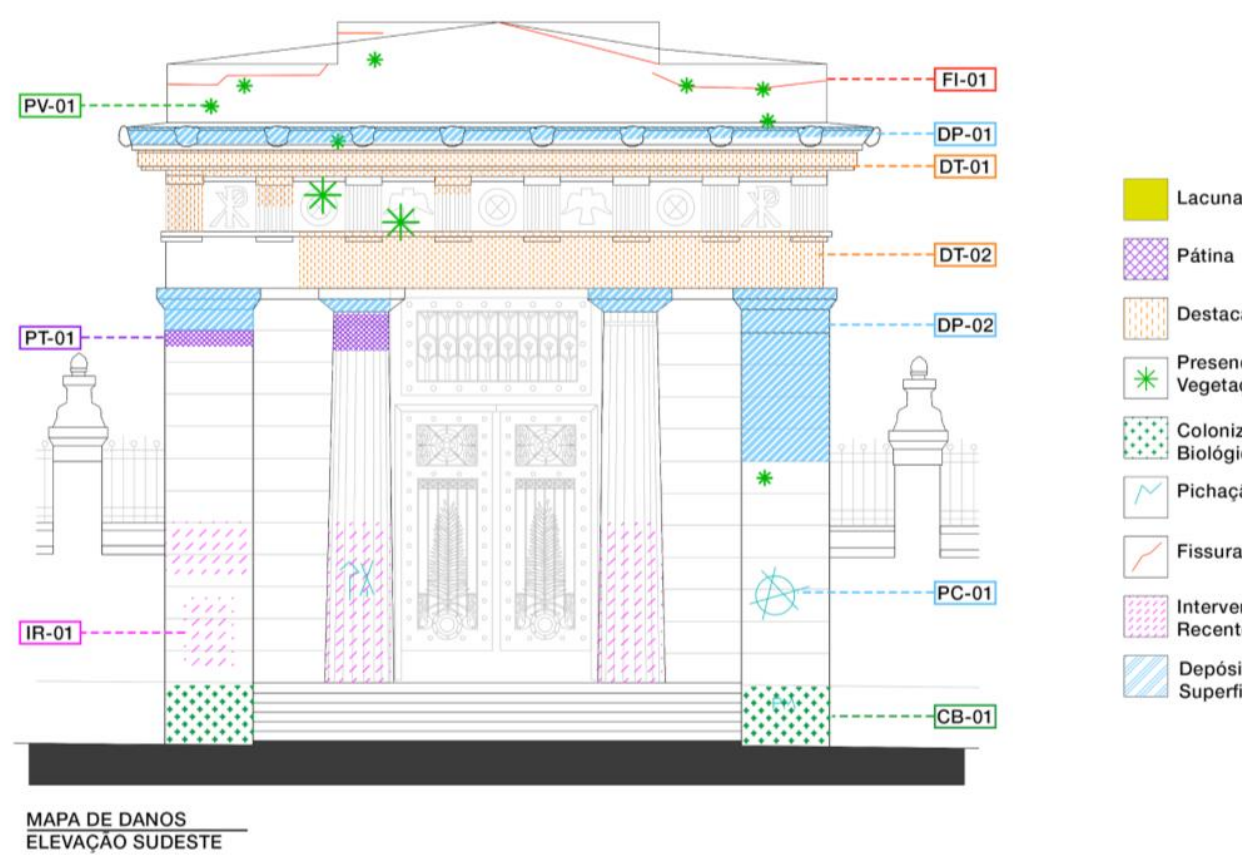

Pátina

Destacamento

Destacamento

Vegetação

Colonização

Biológica

Pichaçăo

Fissura

Intervençấ

Recente

Depósito

Superficial

Figura 6: Mapa de danos da fachada sudeste. Fonte: Autora (2019)

A Figura 7 mostra os danos identificados na fachada noroeste, cujo estado de conservação é o pior dentre as quatro fachadas. Nessa fachada, há uma laje em nível mais alto em relação à calçada que apresenta problemas de impermeabilização que possivelmente está prejudicando a conservação do edifício.

Os principais danos identificados na fachada foram: PV-02, identificada nas fissuras da cobertura, nas conexões entre os adornos de argamassa armada e o friso. A maioria dos indivíduos vegetais são de porte pequeno ou médio. LC-01 (lacuna), verificadas nos locais onde o processo de destacamento de tinta e argamassa já estão num estado mais avançado, de modo a criar lacunas de argamassa e expondo a estrutura em alvenaria. FI-02, encontrada nas platibandas da cobertura de concreto sob a forma de fissuras horizontais ou que acompanham o caimento da laje de concreto. DP-03, observado em toda a cornija como sujidades e um pouco de desgaste da argamassa. A presença da via com intenso trânsito de automóveis e a localização do pórtico favorecem na causa dessas manchas. DT-04, identificada através da termografia (Figura 8 manchas em amarelo), na qual foi possível verificar que a região em volta da lacuna está apresentando destacamento de argamassa. Em DT-04, identificou-se destacamento de tinta generalizado na fachada, possivelmente pela maior incidência de radiação solar que favorece o envelhecimento da tinta. Em FI-03, observou-se grandes área de fissura, porém não foi possível identificar a se ela é superficial, na camada de tinta, ou se está manifestada na camada de argamassa também. CB-02, localizada na região mais próxima ao solo e nos detalhes do friso, criando manchas esverdeadas ou escuras. 

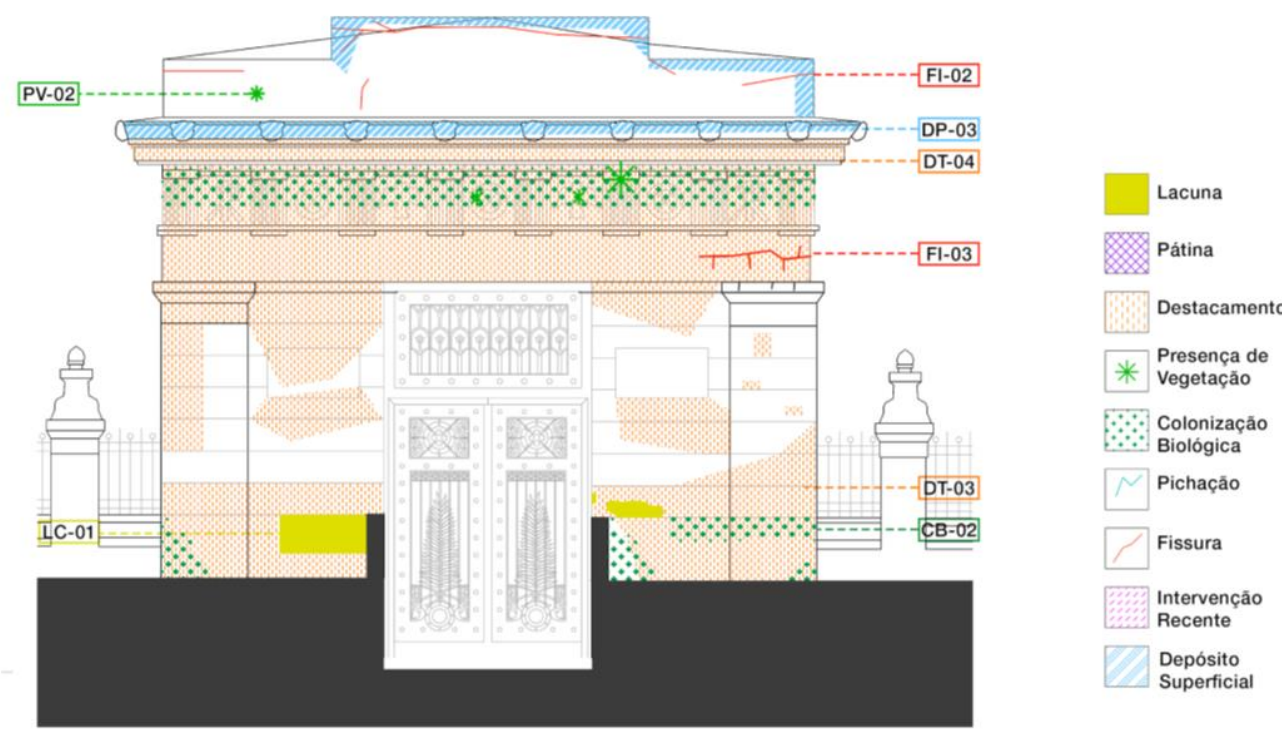

\section{MAPA DE DANOS} ELEVAÇAO NOROESTE

Figura 7: Mapa de danos da fachada noroeste. Fonte: Autora (2019)
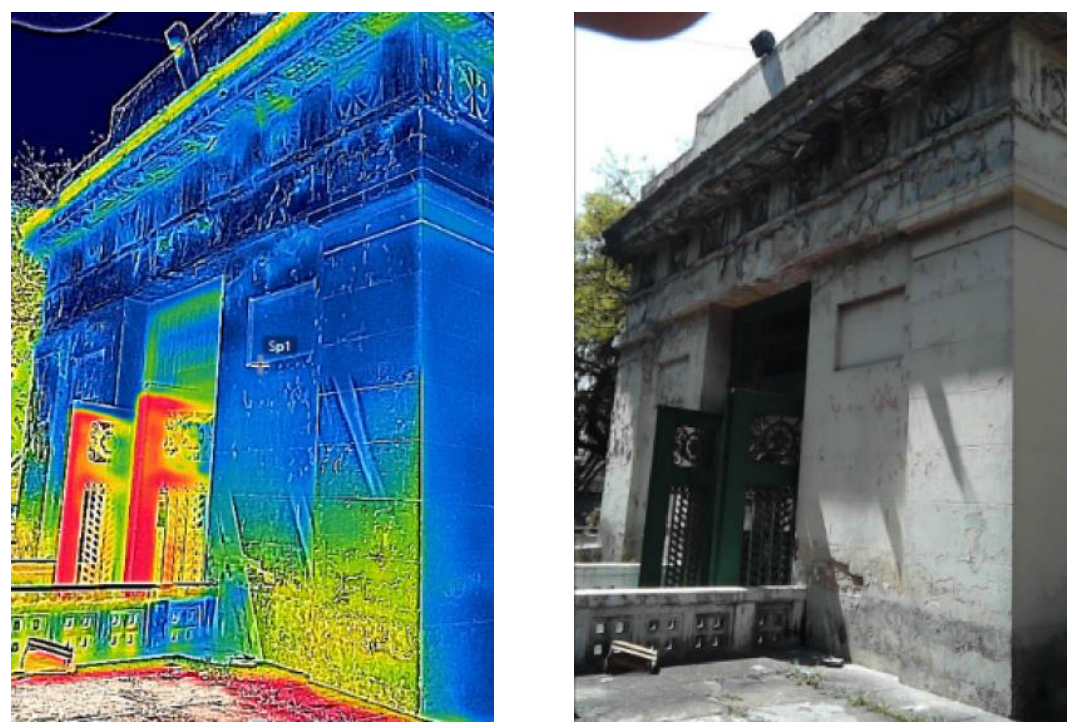

Figura 8: Termografia da fachada noroeste. Fonte: Fabiana Oliveira (2019)

Na Figura 9, estão mapeados os danos da fachada nordeste e sudoeste. A fachada sudoeste, devido à sua orientação, também possui alto grau de deterioração. Já a fachada nordeste é a mais íntegra, por não receber tanta radiação solar direta, apresentando áreas pontuais com manifestações patológicas.

Os principais danos identificados na fachada nordeste foram: PV-0, localizada nas conexões entre os adornos de argamassa armada e o friso. A maioria dos indivíduos vegetais são de porte pequeno. FI-04, encontrada nas platibandas da cobertura de concreto sob a forma de fissuras horizontais ou que acompanham o caimento da laje de concreto. DP-04, observado em toda a cornija como sujidades e um pouco de desgaste da argamassa. Em DT-06, verificou-se leve destacamento de tinta na região do friso. CB-03, representa a presença de uma colméia. CB-04, localizada na região de argamassa e granito mais próxima ao solo, criando manchas esverdeadas ou escuras.

Já os principais danos identificados na fachada sudoeste foram: PV-04, identificada nas fissuras da cobertura, nas conexões entre os adornos de argamassa armada e o friso. A maioria dos indivíduos vegetais são de porte pequeno ou médio. PT-02, manifestada por manchas cor de ferrugem no granito concentradas na região superior do pilar. Em CB-05, 
há manchas esverdeadas ou escuras indicando presença de colonização biológica na argamassa e no granito. Em FI-05, há uma fissura vertical no centro do vão do portão. PC-02, localizada no granito na parte da fachada onde há o acesso pela Rua da Consolação. FI-06, encontrada nas platibandas da cobertura de concreto sob a forma de fissuras horizontais ou que acompanham o caimento da laje de concreto. DP-05, em toda a cornija foi observado depósito superficial de sujidades e um pouco de desgaste da argamassa. Em DT-07, há o destacamento generalizado de tinta na região inferior ao friso, possivelmente pela maior incidência de radiação solar que favorece o envelhecimento da tinta.
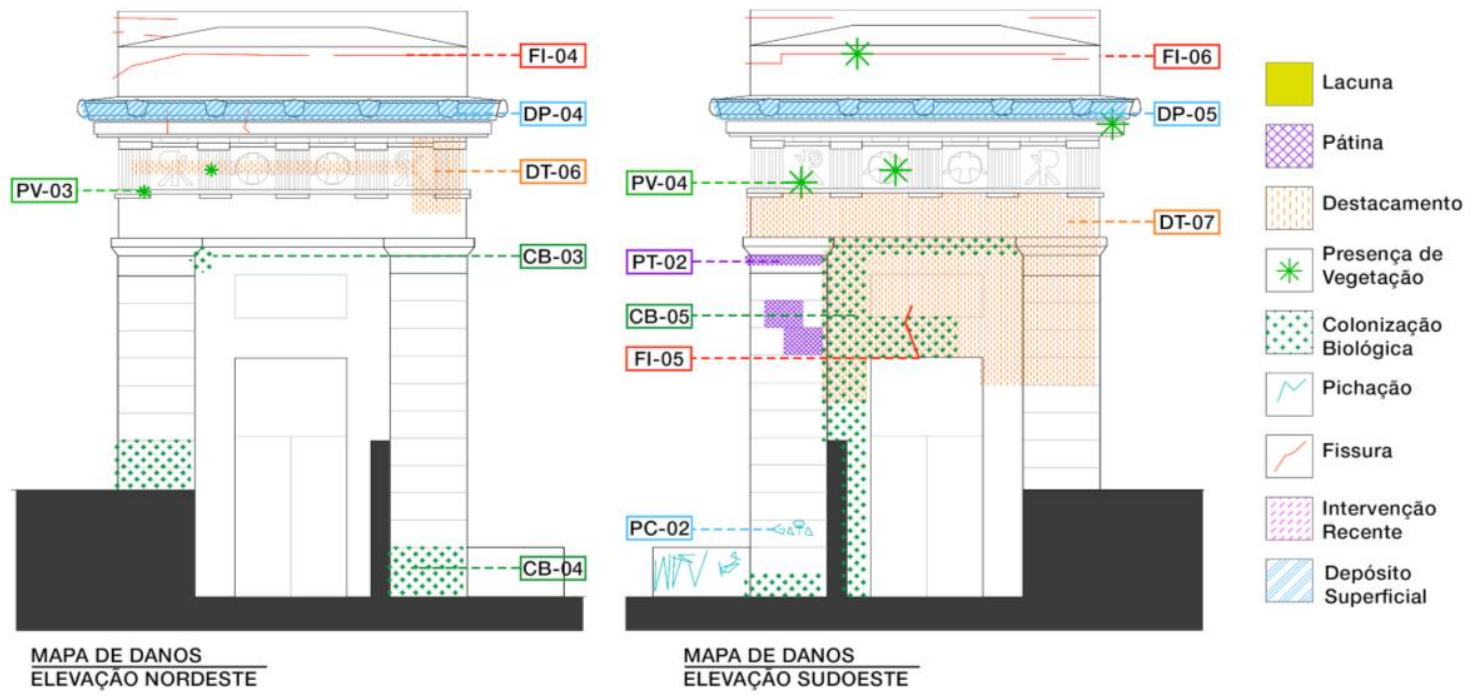

Figura 9: Mapa de danos da fachada nordeste e sudoeste. Fonte: Autora (2019)

Na figura 10, há o mapeamento dos danos na cobertura do pórtico. Foram identificadas fissuras na laje de concreto, cujo formato lembra a um mapa, sugerindo que a causa seja por deslocamento por dilatação térmica. Fissuras transversais na cornija também foram identificadas. Houve a obstrução das gárgulas com argamassa, logo a vazão da água da chuva é feita somente pelo sistema de drenagem interno ao pórtico. Algumas tubulações do sistema de drenagem foram obstruídas por vegetação.

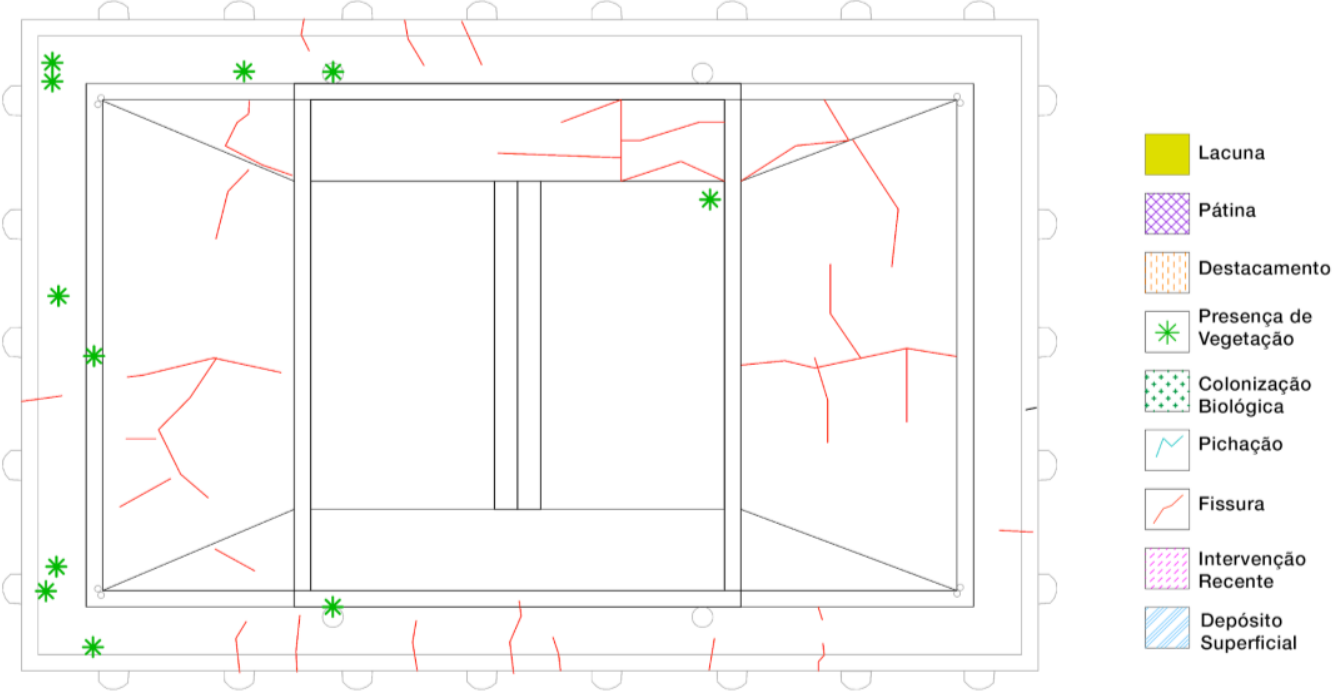

MAPA DE DANOS PLANTA DE COBERTURA

Figura 10: Mapa de danos da cobertura. Fonte: Autora (2019)

Na figura 11, é possível notar uma concentração de umidade e deterioração mais acentuada na fachada voltada para oeste. No mapa de danos da cobertura é possível confirmar que há maior concentração de vegetação e fissura no lado oeste. Logo, para mitigar o processo de deterioração devido à umidade, é necessário propor medidas que garantam a impermeabilização da cobertura e o funcionamento do sistema de drenagem. 


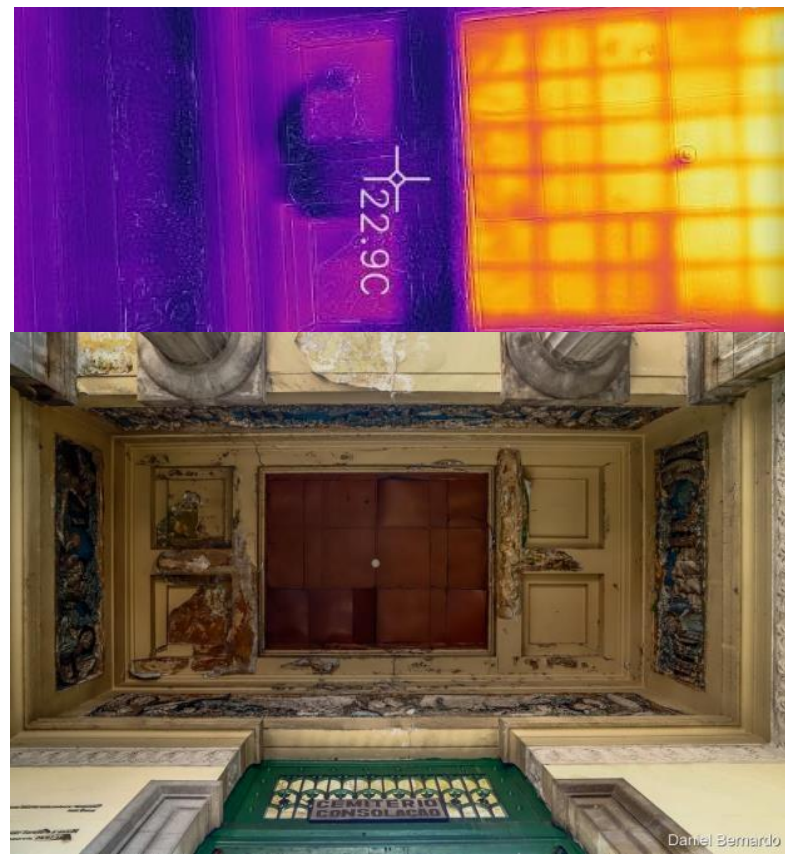

Figura 11: Termografia da cobertura. Fonte: Fabiana Oliveira (2019)

Há o reconhecimento de que para conclusões mais assertivas e um diagnóstico completo é necessário o uso de outros métodos de inspeção. Entretanto, com o mapa de danos realizado com o uso da aerofotogrametria e termografia, permitese a identificação de regiões que necessitam de outros ensaios para identificar a intensidade do dano e validar as hipóteses levantadas sobre os mecanismos de deterioração.

\section{CONCLUSÕES}

O mapeamento possibilitou realizar a etapa de compreensão dos danos (Figura 2) e permite avaliar se as informações são suficientes para propor uma intervenção ou se é necessário outro tipo de ensaio para complementar as informações obtidas. Logo, para a fachada do pórtico, as informações foram suficientes para identificar as causas prováveis das manifestações patológicas. Para a cobertura, é necessário certificar ainda a eficiência do sistema de águas pluviais do pórtico para garantir que a deterioração não provém somente das fissuras identificadas na cobertura.

Nas fachadas, foi possível analisar a influência da poluição advinda do centro urbano que acaba enegrecendo os elementos decorativos da fachada. Além da influência da orientação solar das fachadas na deterioração das camadas de pintura. A especificação de uma tinta de base orgânica não favoreceu na preservação do pórtico, devido à impossibilidade de evaporação da água absorvida pela estrutura e argamassa. A especificação mais adequada é a de tinta a base inorgânica como à base de cal. O entorno é um fator determinante também por haver grande concentração de vegetação, logo há maior facilidade de crescimento de vegetação em tubulações ou em fissuras que pode prejudicar o edifício.

Muitas das manifestações patológicas registradas poderiam ser mitigadas através da manutenção periódica e preventiva, prolongando a vida útil do edifício e postergando grandes intervenções de restauro. Logo, é notável a importância da elaboração do plano de conservação para o edifício em conjunto da administração do cemitério com o objetivo de propor ações de preservação e priorizar intervenções para que o monumento histórico consiga transmitir os valores históricos, estéticos e arquitetônicos da época no qual foi construído.

Os próximos passos a serem adotados serão a sistematização do diagnóstico e elaboração do relatório indicando as intervenções necessárias para melhorar as condições de conservação do Pórtico do Cemitério da Consolação. Ao final, o compilado dos resultados obtidos consistirá no Plano de Conservação. 


\section{AGRADECIMENTOS}

Ao Arqto. Fábio Donadio, do Departamento de Patrimônio Histórico, pela apresentação a esse elemento arquitetônico rico e pelo auxílio no levantamento de bibliografia e bases.

Ao Renan Andrade e Diógenes pelo auxílio no levantamento de imagens por aerofotogrametria e termografia infravermelha.

\section{REFERÊNCIAS}

Arquivo Histórico Municipal de São Paulo.

BONFIM, V. A. C, OLIVEIRA, F. L. A conservação da arquitetura moderna: as fachadas do Edifício Copan. 2019. 337p. Tese (Mestrado) - Faculdade de Arquitetura e Urbanismo da Universidade de São Paulo, São Paulo, 2019.

CARSALADE, F. L. Patrimônio como construção cultural. In: Revista do Patrimônio Histórico e Artístico Nacional HISTÓRICO E ARTÍSTICO NACIONAL, v. 1, p. 137-149, 2017

CARVAlho, M. C. W.; LEMOS, C. A. C. Arquitetura de ramos de azevedo. 1996. 290p. Tese (Doutorado) Faculdade de Arquitetura e Urbanismo da Universidade de São Paulo, São Paulo, 1996.

CONDEPHAAT. Processo de tombamento. Disponível em: <http://condephaat.sp.gov.br > Acesso em: 26 de novembro de 2019

CONPRESP. Processo de tombamento. Disponível em: 〈http://www.prefeitura.sp.gov.br/cidade/upload/>. Acesso em: 26 de novembro de 2019

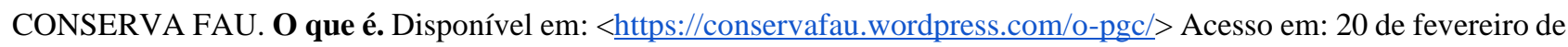
2020.

CORTIZO, E. C.; BARBOSA, M. P.; SOUZA, L. A. C. Estado da Arte da Termografia. Forum Patrimônio: amb. const. e patr. sust. v.2, n.2, Belo Horizonte, mai/ago 2008

CRN - ICR - Istituo centrale per il restauro. NORMAL 1/88 - Alterazioni Macroscopiche dei materiali Lapidei: Lessico. 2. ed. 1987

FUNDAÇÃO CASA RUI BARBOSA. Plano de Conservação Disponível em:

$<$ http://www.casaruibarbosa.gov.br/interna.php?ID_S=218\&ID_M=528> Acesso em: 26 de novembro de 2019

HERITAGE CARE. Guidelines for good practices on preventive conservation, 2019

HIASA, S., BIRGUL, R., CATBAS, F. Investigation of effective utilization of infrared thermography (IRT) through advanced finite element modeling. Construction and Building Materials, V.150. 2017

ICOMOS. Carta de Veneza. May.1964

LOUREIRO, M. A. S. Origem Histórica Dos Cemitérios. São Paulo: SECRETARIA DE SERVIÇOS E OBRAS DA PREFEITURA DO MUNICÍPIO DE SÃO PAULO, 1977

KUHL, B. Notas sobre a Carta de Veneza. Anais Museu Paulista, vol.18, no.2, São Paulo. July/Dec.2010.

TINOCO, J. E. L. Mapa de Danos Recomendações Básicas. Centro de Estudos Avançados da Conservação Integrada. vol. 43. 2009

TIRELLO, R. A., CORREA, R. H. Sistema normativo para mapa de danos de edifícios históricos Aplicado à Lidgerwood Manufactoring Company de Campinas. In: Anais do VI Colóquio Latino-americano sobre Recuperação e Preservação do Patrimônio Industrial. São Paulo, 2012. v. 1. p. 26-44. Disponível em:< http://portal.iphan.gov.br/pagina/detalhes/1194/>. Acesso em: 24.fev.2019. 